\title{
Transmission Congestion Management using a Wind Integrated Compressed Air Energy Storage System
}

\author{
Sadhan Gope \\ Electrical Engineering Department \\ Mizoram University, Tanhril \\ Aizawl, Mizoram, India \\ sadhan.nit@gmail.com
}

\author{
Arup Kumar Goswami \\ Electrical Engineering Department \\ National Institute of Technology \\ Silchar, Assam, India \\ gosarup@gmail.com
}

\author{
Prashant Kumar Tiwari \\ Electrical Engineering Department \\ National Institute of Technology \\ Silchar, Assam, India \\ prashant081.in@gmail.com
}

\begin{abstract}
Transmission congestion is a vital problem in the power system security and reliability sector. To ensure the stable operation of the system, a congestion free power network is desirable. In this paper, a new Congestion Management (CM) technique, the Wind integrated Compressed Air Energy Storage (WCAES) system is used to alleviate transmission congestion and to minimize congestion mitigation cost. The $C M$ problem has been solved by using the Generator Sensitivity Factor (GSF) and the Bus Sensitivity Factor (BSF). BSF is used for finding the optimal location of WCAES in the system. GSF with a Moth Flame Optimization (MFO) algorithm is used for rescheduling the generators to alleviate congestion and to minimize congestion cost by improving security margin. The impact of the WCAES system is tested with a 39 bus system. To validate this approach, the same problem has been solved with a Particle Swarm Optimization (PSO) algorithm and the obtained results are compared with the ones from the MFO algorithm.
\end{abstract}

Keywords-wind farm; compressed air energy storage; bus sensitivity factor; generator sensitivity factor; moth flame optimization algorithm

\section{INTRODUCTION}

Line congestion, especially in a deregulated environment, is one of the most important issues for system operators. A permissible range of power security margin to maintain the system's security network is the necessity. Within fixed thermal limits of transmission lines, thermal generators are rescheduled for congestion alleviation [1]. Recently, requisite amount of works are in process to minimize the congestion in deregulated power market. In [2-4], congestion mitigation techniques are discussed with the integration of Flexible AC Transmission System (FACTS) devices. For diminution of congestion, series FACTS devices are used for enhancement of voltage and transient stability of the system. The generator rescheduling approach is one of the most important techniques in $\mathrm{CM}$ problem. Active power rescheduling is done for congestion mitigation by using the relative electrical distance (RED) approach [5]. Reactive power is also important for congestion mitigation. Real and reactive power rescheduling approach has been used for $\mathrm{CM}$ in [6]. In deregulated electricity market, market flow strategy concepts are often used for congestion management [7-9].
Utilization of wind sources is one of the fastest growing renewable energy sectors in the world. So, it is a priori requirement to analyze the impact of wind energy sources in power system security enhancement. A wind integrated congestion management approach is discussed in [10-11]. Due to the unpredictable nature of wind power, storage devices are essential in the power system security field. The optimal placement of energy storage units to maximize the hourly social welfare in deregulated power system is investigated in [12]. Compressed Air Energy Storage (CAES) system is an important storage technology for storing electricity in modern power system. CAES provides the flexibility of the unpredictable power suppliers by reducing their energy deviations penalties over the entire scheduling period in a deregulated power market [13-14].

In this paper, wind power with CAES has been implemented to mitigate congestion and optimize generator rescheduling cost. CAES is mainly used to deal with the uncertainty of the wind power. The sensitivity of the busses towards congestion is calculated using BSF. Optimal location for WCAES is based on BSF only. Implantation of WCAES checks system violation and reduces system active power rescheduling cost. MFO algorithm and GSF is used to reschedule the generator for mitigating congestion. A 39 bus New England test system is used for validating the proposed method.

\section{WIND INTEGRATED COMPRESSED AIR ENERGY STORAGE (WCAES)}

The main purpose of using CAES with wind farms (WF) is to supply constant power to the grid. Surplus wind power generated (more than contract wind power generation) is stored in the CAES. On the other side, when there is a deficit of contract wind power, the CAES generates the required amount of power of the contract power. Natural gas is used in CAES. Excess WF power generation is used to compress natural air and accumulate in storage device.

When there is a shortage of wind power as per the contractual agreement, compressed air is expanded in a gas turbine, mixed with natural gas and generates the electricity. It is assumed that compression and expansion process takes place at steady state condition. Air pressure, flow of air, potential and kinetic energy 
effects and nuclear or chemical reaction are neglected here. The detailed construction and its operation are given in [15]. Figure 1 shows the CAES implementation flow chart in the proposed congestion mitigation approach.

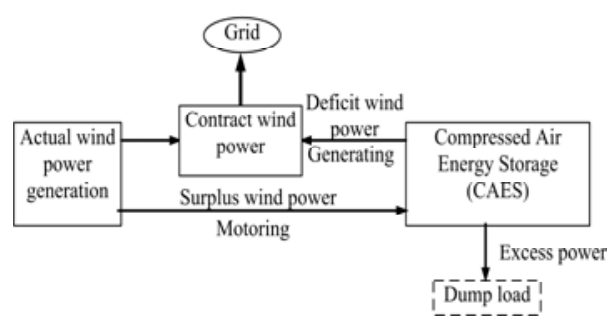

Fig. 1 Implementation flow chart of CAES

III. BSF AND GSF CALCULATION

The active power flow in a congested transmission line at time interval $t$ can be written as [11]:

$$
P_{i j}^{t}=\left|V_{i}^{t}\left\|V_{j}^{t}\right\| Y_{i j}^{t}\right| \cos \left(\varphi_{i j}^{t}-\gamma_{i}^{t}+\gamma_{j}^{t}\right)-\left(V_{i}^{t}\right)^{2} Y_{i j}^{t} \cos \varphi_{i j}^{t}
$$

\section{A. Bus Sensitivity Factor (BSF)}

The change in active power flow in the congested line to the change in nth bus power is called bus sensitivity factor and expressed by [11]:

$$
B S F_{n}^{k}=\frac{\Delta P_{i j}^{t}}{\Delta P_{n}}
$$

The detail BSF derivations are given in [11].

\section{B. Generator Sensitivity Factor (GSF)}

The change in active power flow in the congested line to the change in generator active power supply is called generator sensitivity factor and expressed by [11]:

$$
G S F=\left(\Delta P_{i j}^{t} \Delta P_{G}^{t}\right)
$$

The detail GSF derivations are given in [11].

\section{Problem Formulation}

The main objective of this paper is to minimize the congestion cost of thermal generating units and can be expressed by the following mathematical equation:

$$
\text { Min } \quad \sum_{i=1}^{N G} C_{G i} * \Delta P_{G i}^{t} \quad \forall t=T
$$

The solution of above equation will be obtained when following constraints are satisfied.

$$
\begin{gathered}
\sum_{i=1}^{N G}\left(\left(G S F_{i}\right) \Delta P_{G i}^{t}\right)+M V A_{k}^{0} \leq M V A_{k}^{\max } \quad k=1,2,3,4 \ldots \ldots \ldots . . ., \quad \forall t=T \\
P_{G i}^{t}-P_{G i}^{\min }=\Delta P_{G i}^{\min } \leq \Delta P_{G i}^{t} \leq \Delta P_{G i}^{\max }=P_{G i}^{\max }-P_{G i}^{t} \\
i=1,2,3,4 \ldots \ldots . N G \quad \forall t=T
\end{gathered}
$$

$$
\begin{aligned}
P_{G i}^{\min } & \leq P_{G i}^{t}+\Delta P_{G i}^{t} \leq P_{G i}^{\max } \\
& i=1,2,3,4 \ldots \ldots . N G \quad \forall t=T
\end{aligned}
$$

$\sum_{i=1}^{N G} \Delta P_{G i}^{t}+P_{\text {wind }}^{t}+P_{c g}^{t}-P_{c c}^{t}-P_{D L}^{t}=0 \quad \forall t=T$

$\beta_{c c}^{t}+\beta_{c d}^{t}+\beta_{c g}^{t} \leq 1 \quad \forall t=T$

$0 \leq P_{c c}^{t} \leq P_{c c \max } \beta_{c c}^{t} \quad \forall t=T$

$0 \leq P_{c g}^{t} \leq P_{\max }^{\exp } \beta_{c g}^{t} \quad \forall t=T$

$0 \leq P_{c d}^{t} \leq P_{\max }^{\exp } \beta_{c d}^{t} \quad \forall t=T$

$E_{\text {min }} \leq E_{t} \leq E_{\text {max }} \quad \forall t=T$

$E_{t+1}=E_{t}+t *\left(P_{c c}^{t} * f_{c c}-\frac{P_{c d}^{t}}{f_{c d}}\right) \quad \forall t=T$

$\alpha=f_{c c} * f_{c d}$

$E_{(0)}=E_{\text {int }}$

\section{IMPLEMENTATION OF MOTH FLAME OPTIMIZATION (MFO) ALGORITHM}

Moth Flame Optimization (MFO) algorithm is a nature inspired meta-heuristic population based algorithm proposed in [16]. With the help of transverse orientation method, moth travels in night and maintains a specified angle with respect to moon. Single dimensional or two dimensional or three dimensional or hyper dimensional space vectors is utilized by moth for flying in nature [16]. The set of moths is represented by the following matrix:

$$
\xi=\left[\begin{array}{cccc}
\kappa_{1,1} & \kappa_{1,2} & \ldots \ldots . & \kappa_{1, n} \\
\kappa_{2,1} & \kappa_{2,2} & \ldots \ldots . & \kappa_{2, n} \\
. . & . . & . . & . . \\
. . & . . & . . & . . \\
\kappa_{m, 1} & \kappa_{m, 2} & \ldots \ldots . . & \kappa_{m, n}
\end{array}\right]
$$

The fitness value of all moths is stored in following matrix:

$$
\xi^{f m}=\left[\begin{array}{c}
\xi_{1}^{f m} \\
\xi_{2}^{f m} \\
. \cdot \\
\cdot . \\
\xi_{m}^{f m}
\end{array}\right]
$$


The fitness value of all flames is stored in following matrix:

$$
\xi^{f l}=\left[\begin{array}{cccc}
\xi_{1,1}^{f l} & \xi_{1,2}^{f l} & \ldots \ldots . & \xi_{1, n}^{f l} \\
\xi_{2,1}^{f l} & \xi_{2,2}^{f l} & \ldots \ldots . & \xi_{2, n}^{f l} \\
. . & . . & . . & . . \\
. . & . . & . . & . . \\
\xi_{m, 1}^{f l} & \xi_{m, 2}^{f l} & \ldots \ldots . & \xi_{m, n}^{f l}
\end{array}\right]
$$

As shown in (17) and (19), the moths dimension and flames arrays are equal. The following matrix is utilized for storing the fitness value of flames:

$\xi^{f l m}=\left[\begin{array}{c}\xi_{1}^{f l m} \\ \xi_{2}^{f l m} \\ \cdot \cdot \\ . \cdot \\ \xi_{m}^{f l m}\end{array}\right]$

The actual search agents are moths and flames are the best position of them. Moths travel around the search space to obtain the best position. With this technique, moths do not lose their best fitness solution in any circumstance [16]. A flow chart of the algorithm is shown in Figure 2. To obtain an optimal performance, parameters are set as such: moths number $=30$, flames number $=30$ and iterations number $=300$.

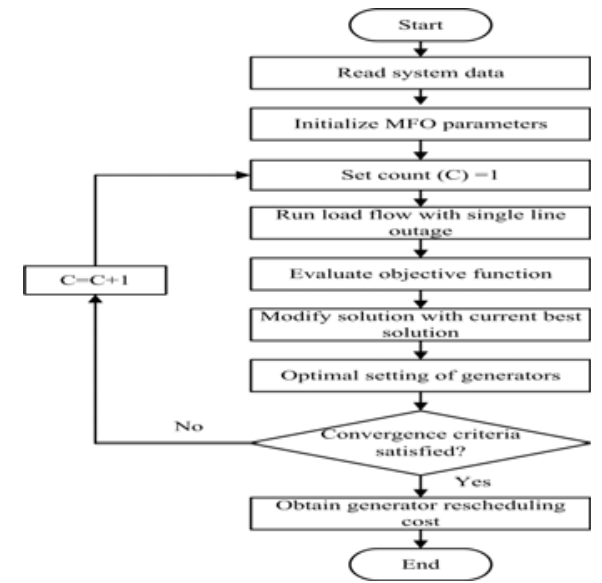

Fig. 2. Implementing flow chart of MFO algorithm

\section{RESULTS AND DISCUSSION}

The proposed CM concept has been investigated on the 39 bus New England system. The 39 bus New England test system data has been taken from [11]. The actual and forecasts wind speed data are taken from [17]. Based on the wind speed data, wind power is calculated and shown in Figure 3. It is assumed, that a total 50 number of wind turbine generators are connected in the wind farm. It is also assumed that all the wind generation units are operating at the same speed. The investment cost of wind power generation is $3.75 \mathrm{\$} / \mathrm{hr}[18]$.

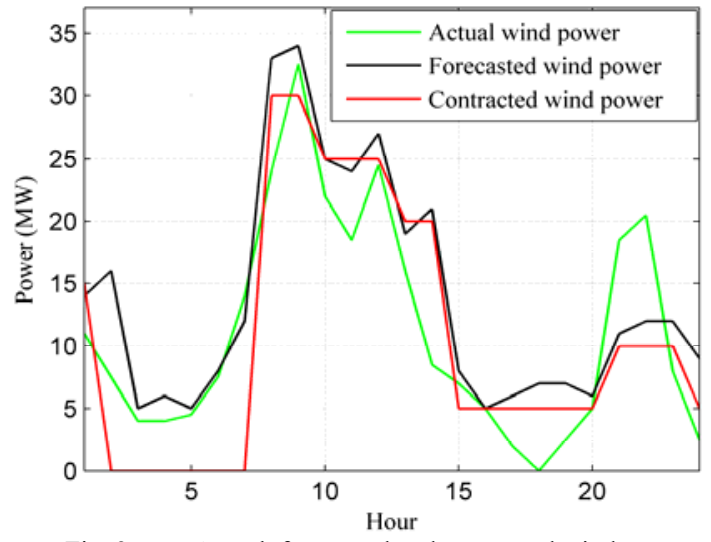

Fig. 3 Actual, forecasted and contracted wind power

The contracted WF power is shown in Figure 3, which is decided based on the forecasted WF power and the load pattern of the system. If there is any deficit on contracted wind power, then CAES storage will fill up that deficit and if there is any surplus of wind power, CAES will compensate that power. If CAES storage is unable to compensate the excess power, then dump load consumes that extra power to stabilize the system. The CAES minimum and maximum energy storage level is considered as $20 \mathrm{MWhr}$ and $100 \mathrm{MWhr}$ respectively. Initial energy level of CAES is assumed as 80 percent of its maximum energy level capaciy. The overall electrical conversion factor of CAES is considered as $70 \%$. The conversion factor of compressor and conversion factor of turbine is assumed as $0.81 \%$ and $0.86 \%$ respectively. The load connected to each bus is assumed time varying and this is implemented by multiplying a load scaling factor (LSF) at each interval. Table I shows the LSF for a 24 hour scheduling period.

TABLE I. LOAD SCALING FACTOR (LSF) FOR 24 HOUR

\begin{tabular}{|c|c|c|c|c|c|}
\hline Hour & LSF & Hour & LSF & Hour & LSF \\
\hline 1 & 1 & 9 & 1.082 & 17 & 1.042 \\
\hline 2 & 0.964 & 10 & 1.089 & 18 & 1.01 \\
\hline 3 & 0.932 & 11 & 1.094 & 19 & 1 \\
\hline 4 & 0.905 & 12 & 1.0965 & 20 & 1.042 \\
\hline 5 & 0.865 & 13 & 1.0976 & 21 & 1.012 \\
\hline 6 & 0.852 & 14 & 1.101 & 22 & 1.065 \\
\hline 7 & 0.896 & 15 & 1.098 & 23 & 1.031 \\
\hline 8 & 1 & 16 & 1.082 & 24 & 1 \\
\hline
\end{tabular}

The proposed congestion management technique is applied to minimize congestion cost, mitigate transmission congestion and improve the security margin. As per proposed approach, the contract wind power has changed in every hour as per the contractual agreement of the wind farm. Generator rescheduling takes the key role in congestion management problem. In the proposed congestion mitigation technique, line (14-34) outage is done for creating line violation in the system.

The (15-16) line is congested due to the (14-34) line outage. So, generators need to be rescheduled based on the GSF to mitigate this congestion. Figure 4 shows the GSF without considering the WCAES system. Before connecting the WCAES system in the system, BSF is calculated and shown in 
Figure 5. Based on the BSF, WCAES system is connected most sensitive bus i.e. bus number 14 in the test system. For connecting WCAES in the test system, BSF is calculated for a total scheduling period i.e. 24 hour in one hour interval and it is seen that each interval BSF is high in bus number 14 . Practically it is not always correct that WCAES system has to be connected in the most sensitive bus. For practical implementation, we have to see the suitable location and sufficient space for WCAES system. If this condition is not satisfied in the most sensitive bus, then we can go for second highest sensitive bus and so on. After connecting the WCAES system, security limit is checked by system operator in the power system. It is seen that the 15-16 line is violated due to the 14-34 line outage. So, the violation has to be mitigated by using generator rescheduling approach.

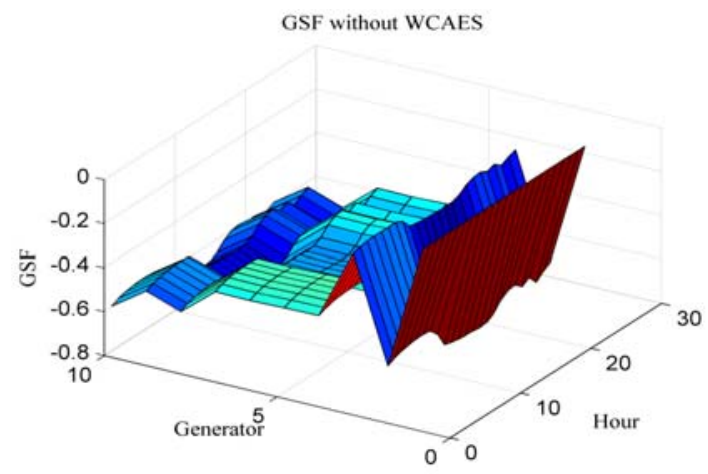

Fig. 4. Generator sensitivity factor without WCAES.

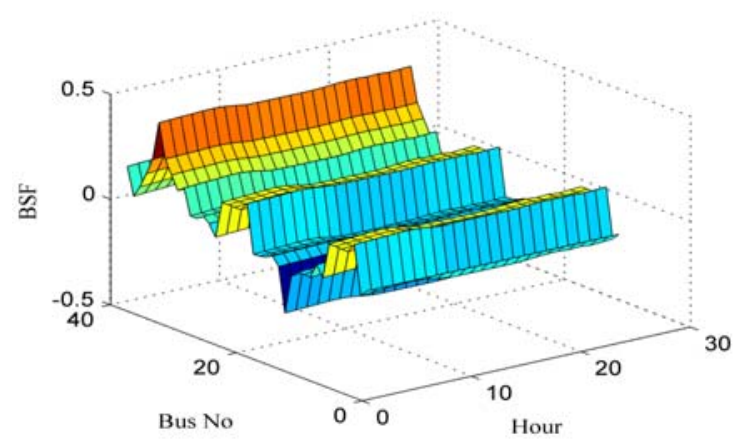

Fig. 5. Bus sensitivity factor without WCAES

For rescheduling the generators, GSF is calculated with integration of WCAES system and shown in Figure 6. Figure 7 shows the congested line (15-16) power flow with and without presence of WCAES system before rescheduling the generators. From Figure 4 and Figure 6, it is seen that the GSF value is less for each scheduling interval with the presence of WCAES system. Less GSF means, less amount power need to be rescheduled for minimizing the congestion. Table III and Table IV represent the amount of active power rescheduling in each interval for mitigating congestion without and with presence of WCAES system respectively.

In each case, generators are rescheduled by using MFO algorithm with help of GSF. In the proposed method, the
WCAES system plays a very important role for mitigating congestion and minimizing rescheduling cost. From Table III it is seen that total rescheduling amount using MFO algorithm for a 24 hour scheduling period without the presence of the WCAES system is $14567.59 \mathrm{MW}$, whereas from Table IV it is seen that total rescheduling amount using the MFO algorithm for the same period with the presence of WCAES system is 14125.34 MW. To show the effectiveness of the WCAES system, it is connected in the most sensitive bus and line violation has been calculated with and without the presence of the WCAES system (Table II). Table II shows the MVA flow (before and after rescheduling) for a 24 hour scheduling period with and without the presence of the WCAES system. From a technical point of view, less generation of a WCAES has been chosen in spite of the fact that a higher rating WCAES may produce a huge impact in the rescheduling process for congestion management.

From Table II, it is seen that for most of the scheduling time the MVA flow is less with the WCAES system. To show the impact of the WCAES system, rescheduling cost is also calculated (Table V). In Table V, it is observed that 2nd to 7th hour intervals, congestion mitigation cost is zero because in that period there is no line violation. It is seen from Table I that load scaling factor is less in 2 nd to 7 th hour interval i.e. system load is less as compared to other interval in the scheduling period. From Table V, it is seen that rescheduling cost using MFO with line outage and without presence of the WCAES system is $13579.76 \$ / 24 \mathrm{hr}$, whereas rescheduling cost with line outage and with the presence of the WCAES system is $13248.43 \$ / 24 \mathrm{hr}$.

TABLE II. MVA FLOW WITH AND WITHOUT WCAES FOR 24 HOUR

\begin{tabular}{|c|c|c|c|c|c|c|}
\hline \multirow{2}{*}{ Hr } & \multicolumn{2}{|c|}{$\begin{array}{c}\text { MVA Flow before } \\
\text { rescheduling }\end{array}$} & \multicolumn{3}{|c|}{ MVA Flow after rescheduling } \\
\cline { 2 - 7 } & \multirow{2}{*}{$\begin{array}{c}\text { Without } \\
\text { WCAES }\end{array}$} & $\begin{array}{c}\text { With } \\
\text { WCAES }\end{array}$ & \multicolumn{2}{|c|}{ Without WCAES } & \multicolumn{2}{c|}{$\begin{array}{c}\text { With } \\
\text { WCAES }\end{array}$} \\
\cline { 5 - 8 } & & PSO & MFO & PSO & MFO \\
\hline 1 & 581 & 569 & 497 & 497 & 496 & 496 \\
\hline 2 & 474 & 474 & $474^{*}$ & $474^{*}$ & $474^{*}$ & $474^{*}$ \\
\hline 3 & 378 & 378 & $378^{*}$ & $378^{*}$ & $378^{*}$ & $378^{*}$ \\
\hline 4 & 298 & 298 & $298^{*}$ & $298^{*}$ & $298^{*}$ & $298^{*}$ \\
\hline 5 & 180 & 180 & $180^{*}$ & $180^{*}$ & $180^{*}$ & $180^{*}$ \\
\hline 6 & 142 & 142 & $142^{*}$ & $142^{*}$ & $142^{*}$ & $142^{*}$ \\
\hline 7 & 272 & 272 & $272^{*}$ & $272^{*}$ & $272^{*}$ & $272^{*}$ \\
\hline 8 & 581 & 557 & 497 & 497 & 496 & 496 \\
\hline 9 & 827 & 807 & 499 & 499 & 499 & 498 \\
\hline 10 & 848 & 832 & 499 & 499 & 499 & 499 \\
\hline 11 & 863 & 847 & 499 & 499 & 499 & 499 \\
\hline 12 & 871 & 855 & 499 & 499 & 499 & 499 \\
\hline 13 & 874 & 862 & 499 & 499 & 498 & 498 \\
\hline 14 & 885 & 873 & 498 & 498 & 497 & 496 \\
\hline 15 & 875 & 874 & 496 & 497 & 496 & 494 \\
\hline 16 & 827 & 826 & 498 & 499 & 496 & 496 \\
\hline 17 & 707 & 704 & 499 & 498 & 496 & 493 \\
\hline 18 & 611 & 607 & 497 & 497 & 489 & 486 \\
\hline 19 & 581 & 577 & 497 & 497 & 496 & 496 \\
\hline 20 & 707 & 704 & 495 & 496 & 483 & 482 \\
\hline 21 & 617 & 609 & 498 & 498 & 494 & 492 \\
\hline 22 & 776 & 770 & 499 & 499 & 499 & 498 \\
\hline 23 & 674 & 667 & 498 & 499 & 498 & 498 \\
\hline 24 & 581 & 577 & 497 & 497 & 496 & 496 \\
\hline & & & & & & \\
\hline
\end{tabular}

*Rescheduling is not required 
TABLE III. GENERATOR RESCHEDULING AMOUNT WITHOUT WCAES USING MFO ALGORITHM FOR 24 HOUR SCHEDULING PERIOD

\begin{tabular}{|c|c|c|c|c|c|c|c|c|c|c|c|}
\hline Time & $\mathbf{G}_{1}(M W)$ & $\mathrm{G}_{2}(\mathrm{MW})$ & $\mathbf{G}_{3}(M W)$ & $\mathrm{G}_{\mathbf{4}}(\mathrm{MW})$ & $\mathrm{G}_{5}(M W)$ & $\mathbf{G}_{6}(M W)$ & $\mathbf{G}_{7}(\mathbf{M W})$ & $\mathrm{G}_{8}(\mathrm{MW})$ & $\mathbf{G}_{9}(M W)$ & $\mathrm{G}_{10}(\mathrm{MW})$ & Total (MW) \\
\hline 1 & -75.34 & -33.61 & -45.45 & NR & NR & NR & NR & 18.33 & -105.03 & 250 & 527.77 \\
\hline 2 & NR & NR & NR & NR & NR & NR & NR & NR & NR & NR & 0 \\
\hline 3 & NR & NR & NR & NR & NR & NR & NR & NR & NR & NR & 0 \\
\hline 4 & NR & NR & NR & NR & NR & NR & NR & NR & NR & NR & 0 \\
\hline 5 & NR & NR & NR & NR & NR & NR & NR & NR & NR & NR & 0 \\
\hline 6 & NR & NR & NR & NR & NR & NR & NR & NR & NR & NR & 0 \\
\hline 7 & NR & NR & NR & NR & NR & NR & NR & NR & NR & NR & 0 \\
\hline 8 & -75.34 & -33.61 & -45.45 & NR & NR & NR & NR & 18.33 & -105.03 & 250 & 527.77 \\
\hline 9 & -130.24 & 126.75 & 36.6 & 68.72 & 88.92 & 56.54 & 78.3 & 110.67 & -101.05 & 248.2 & 1045.99 \\
\hline 10 & -143.87 & 134.56 & 32.65 & 86.11 & 76.87 & 51.82 & 80.12 & 115.07 & -99.81 & 250 & 1070.88 \\
\hline 11 & -148.24 & 134.76 & 27.89 & 56.67 & 90.45 & 60.87 & 76.34 & 130.49 & -106.68 & 250 & 1082.39 \\
\hline 12 & -152.88 & 140.21 & 30.12 & 68.56 & 86.8 & 42.12 & 79.21 & 136.65 & -102.9 & 249.67 & 1089.12 \\
\hline 13 & -137.87 & 154.66 & 20.9 & 90.28 & 100.01 & 46.23 & 75.98 & 130.08 & -100.21 & 240.22 & 1096.44 \\
\hline 14 & -160.07 & 144.21 & 24.6 & 81.22 & 92.82 & 48.54 & 81.53 & 124.04 & -89.21 & 253.59 & 1099.83 \\
\hline 15 & -136.87 & 154.63 & 20.92 & 89.88 & 99.89 & 46.23 & 75.37 & 130.24 & -100.24 & 243.25 & 1097.52 \\
\hline 16 & -130.24 & 126.75 & 36.6 & 68.72 & 88.92 & 56.54 & 78.3 & 110.67 & -101.05 & 248.2 & 1045.99 \\
\hline 17 & -87.8 & 37.93 & -18.69 & 2.03 & 84.02 & NR & NR & 97.44 & -81.01 & 232.32 & 641.24 \\
\hline 18 & -78.43 & 35.33 & -20.62 & NR & 76.76 & NR & NR & 99.23 & -83.66 & 204.65 & 598.68 \\
\hline 19 & -75.34 & -33.61 & -45.45 & NR & NR & NR & NR & 18.33 & -105.03 & 250 & 527.77 \\
\hline 20 & -86.8 & 38.93 & -17.69 & NR & 88.02 & NR & NR & 100 & -80.01 & 250 & 662.49 \\
\hline 21 & -86.34 & -102.61 & -45.67 & NR & NR & NR & NR & 25.33 & -96.36 & 248.23 & 604.54 \\
\hline 22 & -95.2 & 45.93 & -27.69 & 14.67 & 98.45 & NR & NR & 99.45 & -68.9 & 252.6 & 702.89 \\
\hline 23 & -78.43 & 45.33 & -28.62 & NR & 80.23 & NR & NR & 83.56 & -95.67 & 206.67 & 618.51 \\
\hline 24 & -75.34 & -33.61 & -45.45 & NR & NR & NR & NR & 18.33 & -105.03 & 250 & 527.77 \\
\hline \multicolumn{11}{|c|}{ Total } & 14567.59 \\
\hline
\end{tabular}

TABLE IV. GENERATOR RESCHEDULING AMOUNT WITH WCAES USING MFO ALGORITHM FOR 24 HOUR SCHEDULING PERIOD

\begin{tabular}{|c|c|c|c|c|c|c|c|c|c|c|c|}
\hline Time & $\mathrm{G}_{1}(\mathrm{MW})$ & $\mathbf{G}_{2}(\mathrm{MW})$ & $\mathbf{G}_{3}(M W)$ & $\mathrm{G}_{\mathbf{4}}(\mathrm{MW})$ & $\mathrm{G}_{5}(\mathrm{MW})$ & $\mathrm{G}_{6}(\mathrm{MW})$ & $\mathrm{G}_{7}(\mathbf{M W})$ & $\mathrm{G}_{8}(M W)$ & $\mathrm{G}_{9}(M W)$ & $G_{10}(M W)$ & Total (MW) \\
\hline 1 & -72.34 & -35.61 & -43.45 & NR & NR & NR & NR & 15.12 & -97.65 & 239.8 & 503.97 \\
\hline 2 & NR & NR & NR & NR & NR & NR & NR & NR & NR & NR & 0 \\
\hline 3 & NR & NR & NR & NR & NR & NR & NR & NR & NR & NR & 0 \\
\hline 4 & NR & NR & NR & NR & NR & NR & NR & NR & NR & NR & 0 \\
\hline 5 & NR & NR & NR & NR & NR & NR & NR & NR & NR & NR & 0 \\
\hline 6 & NR & NR & NR & NR & NR & NR & NR & NR & NR & NR & 0 \\
\hline 7 & NR & NR & NR & NR & NR & NR & NR & NR & NR & NR & 0 \\
\hline 8 & -68.36 & -35.48 & -37.65 & NR & NR & NR & NR & 22.46 & -93.03 & 235.89 & 492.87 \\
\hline 9 & -122.24 & 117.75 & 38.62 & 65.23 & 82.92 & 57.34 & 72.3 & 112.63 & -96.05 & 242.2 & 1007.28 \\
\hline 10 & -127.44 & 122.85 & 38.6 & 67.72 & 86.92 & 58.54 & 74.3 & 113.67 & -101.05 & 246.2 & 1037.29 \\
\hline 11 & -134.87 & 128.56 & 32.65 & 76.11 & 84.87 & 51.82 & 80.12 & 115.07 & -99.81 & 248.5 & 1052.38 \\
\hline 12 & -143.87 & 132.56 & 34.75 & 75.21 & 86.87 & 50.82 & 80.12 & 115.17 & -100.21 & 247.2 & 1066.78 \\
\hline 13 & -145.24 & 134.76 & 27.89 & 56.67 & 88.45 & 55.87 & 76.34 & 130.49 & -105.68 & 249.1 & 1070.49 \\
\hline 14 & -147.88 & 136.21 & 33.12 & 71.66 & 85.8 & 46.12 & 79.21 & 132.65 & -102.9 & 248.3 & 1083.85 \\
\hline 15 & -139.87 & 141.63 & 20.92 & 89.88 & 95.89 & 46.23 & 75.37 & 130.24 & -100.24 & 245.25 & 1085.52 \\
\hline 16 & -122.24 & 120.75 & 36.6 & 68.72 & 88.92 & 56.54 & 78.3 & 107.67 & -101.05 & 248.2 & 1028.99 \\
\hline 17 & -84.8 & 37.93 & $\begin{array}{l}-19.69 \\
\end{array}$ & NR & 81.02 & NR & NR & 95.44 & -79.01 & 230.32 & 628.21 \\
\hline 18 & -81.44 & 35.33 & -20.62 & NR & 76.76 & NR & NR & 94.22 & -73.66 & 204.65 & 586.68 \\
\hline 19 & -68.36 & -35.48 & -37.65 & NR & NR & NR & NR & 22.46 & -93.03 & 235.89 & 492.87 \\
\hline 20 & -84.8 & 37.93 & -19.69 & NR & 81.02 & NR & NR & 95.44 & -79.01 & 230.32 & 628.21 \\
\hline 21 & -80.44 & 35.33 & -20.62 & NR & 74.76 & NR & NR & 95.22 & -78.66 & 203.65 & 588.68 \\
\hline 22 & -89.2 & 45.93 & -27.69 & 14.67 & 92.45 & NR & NR & 98.45 & -68.9 & 245.6 & 682.89 \\
\hline 23 & -75.43 & 45.33 & -25.62 & NR & 78.23 & NR & NR & 83.56 & -80.67 & 206.67 & 595.51 \\
\hline 24 & -68.36 & -35.48 & -37.65 & NR & NR & NR & NR & 22.46 & -93.03 & 235.89 & 492.87 \\
\hline \multicolumn{11}{|c|}{ Total } & 14125.34 \\
\hline
\end{tabular}

For calculating rescheduling cost with the presence of the WCAES system, wind power investment cost is also considered. For analyzing this study, we are considering WCAES system supplies power mainly from wind farm. From Table $\mathrm{V}$, it is seen that by using MFO, congestion cost reduced by $331.33 \$ / 24 \mathrm{hr}$ with the presence of the WCAES system compared to without the presence of the WCAES system in the scheduling period. From Table V, it is also seen that rescheduling cost using PSO with line outage and without presence of WCAES system is $13584.43 \$ / 24 \mathrm{hr}$, where as rescheduling cost with line outage and with the presence of the
WCAES system is $13252.97 \$ / 24 \mathrm{hr}$, which is slightly higher than the MFO algorithm results. Table VI shows the losses and minimum voltage of the system. From Table VI, it is observed that system voltage is better and losses are less in presence of the WCAES system. Improved voltage profile indicates the better stability of the system after congestion management.

Figure 8 shows the CAES operation for a 24 hour scheduling period. It shows the power and energy exchange for the entire scheduling period. 
TABLE V. RESCHEDULING COST (\$/H) FOR 24 HOUR SCHEDULING PERIOD

\begin{tabular}{|c|c|c|c|c|}
\hline \multirow{2}{*}{ Hour } & \multicolumn{2}{|c|}{$\begin{array}{c}\text { Congestion cost (\$/h) } \\
\text { using PSO } \\
\end{array}$} & \multicolumn{2}{|c|}{$\begin{array}{c}\text { Congestion cost (\$/h)using } \\
\text { MFO }\end{array}$} \\
\hline & $\begin{array}{l}\text { Without } \\
\text { WCAES }\end{array}$ & $\begin{array}{c}\text { With } \\
\text { WCAES }\end{array}$ & $\begin{array}{l}\text { Without } \\
\text { WCAES }\end{array}$ & $\begin{array}{c}\text { With } \\
\text { WCAES }\end{array}$ \\
\hline 1 & 231.54 & 215.12 & 231.45 & 214.76 \\
\hline 2 & 0 & 0 & 0 & 0 \\
\hline 3 & 0 & 0 & 0 & 0 \\
\hline 4 & 0 & 0 & 0 & 0 \\
\hline 5 & 0 & 0 & 0 & 0 \\
\hline 6 & 0 & 0 & 0 & 0 \\
\hline 7 & 0 & 0 & 0 & 0 \\
\hline 8 & 231.54 & 215.12 & 231.45 & 214.76 \\
\hline 9 & 1175.67 & 1108.24 & 1175.39 & 1108.53 \\
\hline 10 & 1190.21 & 1183.94 & 1189.76 & 1183.6 \\
\hline 11 & 1202.84 & 1189.65 & 1202.89 & 1189.28 \\
\hline 12 & 1216.06 & 1198.16 & 1215.65 & 1197.65 \\
\hline 13 & 1227.76 & 1202.57 & 1227.73 & 1202.13 \\
\hline 14 & 1243.59 & 1225.26 & 1242.94 & 1224.87 \\
\hline 15 & 1228.64 & 1225.68 & 1228.12 & 1225.62 \\
\hline 16 & 1176.33 & 1173.18 & 1175.39 & 1172.74 \\
\hline 17 & 575.98 & 567.48 & 576.25 & 567.57 \\
\hline 18 & 324.17 & 313.08 & 323.77 & 312.86 \\
\hline 19 & 231.54 & 215.12 & 231.45 & 214.74 \\
\hline 20 & 594.45 & 567.88 & 594.05 & 567.57 \\
\hline 21 & 256.92 & 227.72 & 256.49 & 227.65 \\
\hline 22 & 868.86 & 854.74 & 868.96 & 854.88 \\
\hline 23 & 376.79 & 354.91 & 376.57 & 354.48 \\
\hline 24 & 231.54 & 215.12 & 231.45 & 214.74 \\
\hline $\begin{array}{c}\text { Total } \\
\text { cost } \\
(\$ / 24 \mathrm{hr})\end{array}$ & 13584.43 & 13252.97 & 13579.76 & 13248.43 \\
\hline
\end{tabular}

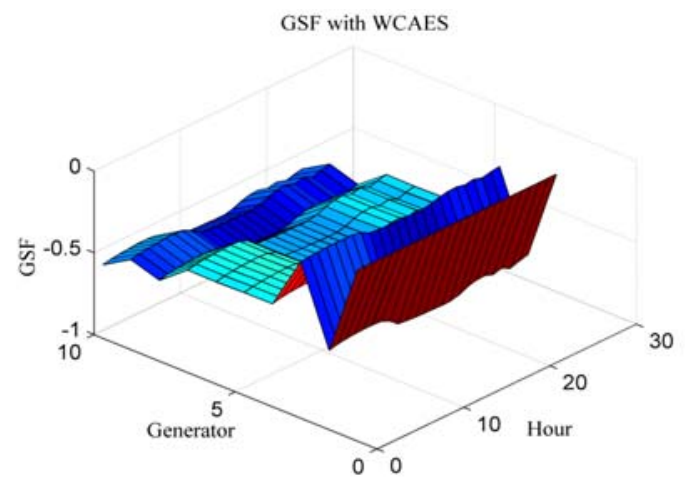

Fig. 6. Generator sensitivity factor with WCAES

Congested line power llow belore rescheduling

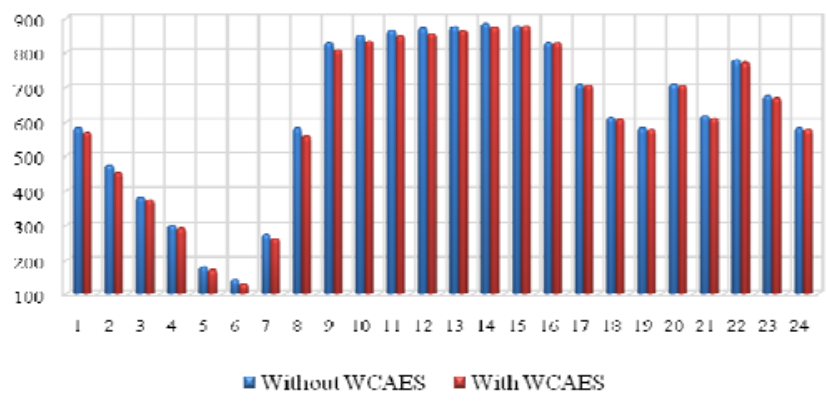

Fig. 7. MVA flow in congested line with and without WCAES
TABLE VI. SYSTEM PARAMETERS AFTER RESCHEDULING USING MFO ALGORITHM

\begin{tabular}{|c|c|c|c|c|}
\hline \multirow{2}{*}{ Hour } & \multicolumn{2}{|c|}{ Without WCAES } & \multicolumn{2}{c|}{ With WCAES } \\
\cline { 2 - 5 } & $\boldsymbol{V}_{\boldsymbol{m i n}}(\boldsymbol{p} \cdot \boldsymbol{u})$ & $\boldsymbol{P}_{\text {loss }}(\boldsymbol{M} \boldsymbol{W})$ & $\boldsymbol{V}_{\boldsymbol{m i n}}(\boldsymbol{p} \cdot \boldsymbol{u})$ & $\boldsymbol{P}_{\text {loss }}(\boldsymbol{M} \boldsymbol{W})$ \\
\hline 1 & 0.945 & 58.672 & 0.967 & 58.254 \\
\hline 2 & 0.946 & 58.025 & $0.946^{*}$ & $58.025^{*}$ \\
\hline 3 & 0.947 & 58.342 & $0.947^{*}$ & $58.342^{*}$ \\
\hline 4 & 0.947 & 58.439 & $0.947^{*}$ & $58.439^{*}$ \\
\hline 5 & 0.949 & 58.023 & $0.949^{*}$ & $58.023^{*}$ \\
\hline 6 & 0.954 & 58.025 & $0.954^{*}$ & $58.025^{*}$ \\
\hline 7 & 0.951 & 58.351 & $0.951^{*}$ & $58.351^{*}$ \\
\hline 8 & 0.945 & 58.672 & 0.964 & 57.746 \\
\hline 9 & 0.936 & 59.045 & 0.941 & 58.862 \\
\hline 10 & 0.935 & 59.086 & 0.940 & 58.889 \\
\hline 11 & 0.935 & 59.087 & 0.941 & 58.874 \\
\hline 12 & 0.934 & 59.088 & 0.940 & 58.872 \\
\hline 13 & 0.934 & 59.166 & 0.935 & 59.132 \\
\hline 14 & 0.934 & 59.212 & 0.936 & 59.120 \\
\hline 15 & 0.935 & 59.091 & 0.938 & 59.001 \\
\hline 16 & 0.935 & 59.042 & 0.937 & 58.988 \\
\hline 17 & 0.946 & 58.762 & 0.948 & 58.523 \\
\hline 18 & 0.948 & 58.688 & 0.952 & 58.547 \\
\hline 19 & 0.945 & 58.672 & 0.967 & 58.455 \\
\hline 20 & 0.946 & 58.674 & 0.952 & 58.465 \\
\hline 21 & 0.948 & 58.579 & 0.974 & 58.023 \\
\hline 22 & 0.952 & 58.564 & 0.976 & 58.012 \\
\hline 23 & 0.958 & 58.485 & 0.978 & 58.016 \\
\hline 24 & 0.945 & 58.672 & 0.966 & 58.255 \\
\hline
\end{tabular}

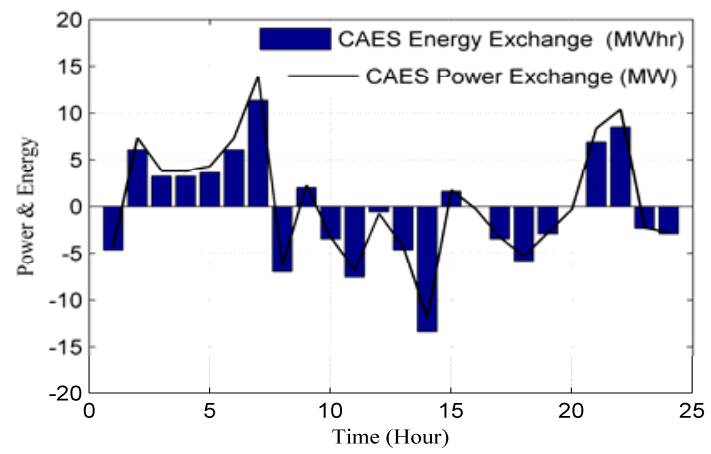

Fig. 8. CAES operational

\section{CONCLUSION}

Congestion in transmission systems is a real life problem and a burning issue in power sector reliability. Misbalanced power generation and demand is the cause of congestion. To maintain the balanced system profile for a long run, alleviation of congestion is essential. The key element for the solution considered in this paper is the incorporation of WCAES. This helps to not only mitigate congestion but also to reduce congestion cost. The obtained results reflect the effective utilization of WCAES in the 39 bus New England test system. BSF is used for the optimal placement of WCAES in the most sensitive bus of the system. GSF with MFO algorithm in the presence of WCAES is implemented for generation rescheduling and to mitigate transmission congestion. Results obtained by the MFO algorithm are compared with ones obtained from applying the PSO algorithm and it is shown that the MFO algorithm gives slightly better results. The proposed 
method is used for a 24 hour scheduling period in order to explain the effectiveness of the technique more accurately. Less congestion cost and reduced line MVA flows are achieved. The proposed approach is economically feasible and easy to incorporate.

\section{NOMENCLATURE}

\begin{tabular}{|c|c|}
\hline $\mathrm{V}_{\mathrm{i}}^{\mathrm{t}}$ & Voltage magnitude at bus $-i$ at $\mathrm{t}^{\text {th }}$ time interval \\
\hline $\mathrm{V}_{\mathrm{j}}^{\mathrm{t}}$ & Voltage magnitude at bus $-j$ at $\mathrm{t}^{\text {th }}$ time interval $t$ \\
\hline$\gamma_{i}$ & Angle at bus- $i$ at $t^{\text {th }}$ time interval \\
\hline$\Delta \mathrm{P}_{\mathrm{ij}}^{\mathrm{t}}$ & Change in active power flow at $\mathrm{t}^{\text {th }}$ interval \\
\hline$C_{G i}$ & Congestion cost of individual generator \\
\hline$P_{G}^{\max }$ & Maximum active power generation limits \\
\hline $\operatorname{MV}_{a x} V A_{k}^{m}$ & Maximum MVA flow limit of $k^{\text {th }}$ transmission line \\
\hline$P_{c g}{ }^{t}$ & $\begin{array}{l}\text { Power generation from CAES in simple cycle mode } \\
\text { at time interval } t \text {. }\end{array}$ \\
\hline$P_{c d}{ }^{t}$ & $\begin{array}{l}\text { Power generation from CAES in discharging mode } \\
\text { at time interval } t\end{array}$ \\
\hline$\alpha$ & Electrical conversion factor of CAES \\
\hline $\mathrm{P}_{\mathrm{ccmax}}$ & Maximum compression capacity of compressor, \\
\hline $\mathrm{E}_{\min }$ & Minimum level of air storage \\
\hline $\mathrm{E}_{\text {int }}$ & Initial level of air storage \\
\hline$Y_{i j}$ & $\begin{array}{l}\text { Magnitude of } i j^{\text {th }} \text { element of } Y_{B u s} \text { matrix at } t^{\text {th }} \text { time } \\
\text { interval }\end{array}$ \\
\hline$\gamma_{j}$ & Angle at bus- $j$ at $\mathrm{t}^{\text {th }}$ time interval \\
\hline$\varphi_{i j}$ & $\begin{array}{l}\text { Angle of } Y_{B u s} \text { matrix at } i j^{\text {th }} \text { element at } t^{\text {th }} \text { time } \\
\text { interval }\end{array}$ \\
\hline$\Delta P_{G i}^{t}$ & $\begin{array}{l}\text { Active power adjustment of individual generator at } \\
\text { time interval } t \text {, }\end{array}$ \\
\hline$P_{G}^{\min }$ & Minimum active power generation limits \\
\hline$M V A_{k}{ }^{0}$ & Actual MVA flow in the transmission line $k$ \\
\hline$P_{\text {wind }}{ }^{t}$ & Wind power generation at time interval $t$ \\
\hline$P_{c c}^{t}$ & Power consumption by CAES in the time interval $t$ \\
\hline$\beta_{c c}^{t}$ & Charging mode of CAES at $\mathrm{t}^{\text {th }}$ interval, $[0$ or 1$]$ \\
\hline$\beta_{c d}^{t}$ & Discharging mode of CAES at $\mathrm{t}^{\text {th }}$ interval, $[0$ or 1$]$ \\
\hline$\beta_{c g}^{t}$ & Simple cycle mode of CAES at $\mathrm{t}^{\text {th }}$ interval, [0 or 1$]$ \\
\hline $\mathrm{P}_{\max } \exp$ & Maximum generation capacity of expander \\
\hline $\mathrm{P}_{\mathrm{DL}}^{\mathrm{t}}$ & Dump load power consumption at time interval $t$ \\
\hline $\mathrm{E}_{\max }$ & Maximum level of air storage \\
\hline$t$ & Index of hour or interval \\
\hline$m$ & Number of moths \\
\hline$n$ & Number of variables \\
\hline$\xi$ & Position vector matrix of moth \\
\hline$\xi^{f m}$ & Fitness vector matrix of moth \\
\hline$\xi^{f l}$ & Position vector matrix of flame \\
\hline$\xi^{f l m}$ & Fitness vector matrix of flame \\
\hline$\kappa_{m, n}$ & Position of moth \\
\hline$\xi_{m}^{f m}$ & Fitness of moth \\
\hline
\end{tabular}

\begin{tabular}{|ll|}
$\xi_{m, n}^{f l}$ & Position of flame \\
$\xi_{m}^{f l m}$ & Fitness of flame \\
$f_{c c}$ & Conversion factor of compressor \\
$f_{c d}$ & Conversion factor of turbine \\
\hline
\end{tabular}

\section{REFERENCES}

[1] S. Dutta, S. P Singh, "Optimal rescheduling of generators for congestion management based on particle swarm optimization", IEEE Transaction on Power System, Vol. 23, pp. 1560-1569, 2008

[2] A. Kumar, C. Sekhar, "Congestion management with FACTS devices in deregulated electricity markets ensuring loadability limit", Electrical Power and Energy Systems, Vol. 46, pp. 258-273, 2013

[3] M. Esmaili, H. A. Shayanfar, R. Moslemi, "Locating series FACTS devices for multi-objective congestion management improving voltage and transient stability", European Journal of Operational Research, Vol. 236, pp. 763-773, 2014

[4] A. Kumar, R. K. Mittapalli, "Congestion management with generic load model in hybrid electricity markets with FACTS devices", Electrical Power and Energy Systems, Vol. 57, pp. 49-63, 2014

[5] G. Yesuratnam, D. Thukaram, "Congestion management in open access based on relative electrical distances using voltage stability criteria," Electrical Power Systems Research, Vol. 77, pp. 1608-1618, 2007

[6] A. Kumar, S. C. Srivastava, S. N. Singh, "A zonal congestion management approach using real and reactive power rescheduling", IEEE Transaction on Power Systems, Vol. 19, pp. 554-562, 2004

[7] A. Kumar, S. C. Srivastava, S. N. Singh, "Congestion management in competitive power market: A bibliographical survey", Electrical Power Systems Research, Vol. 76, pp. 153-164, 2005

[8] C. Luo, Y. Hou, J. Wen, S. Cheng, "Assessment of Market Flows for Interregional Congestion Management in Electricity Markets", IEEE Transactions on Power Systems, Vol. 29, pp. 1673-1682, 2014

[9] A. K. Singh, S. K. Parida, "Congestion management with distributed generation and its impact on electricity market", Electrical Power and Energy Systems, Vol. 48, pp 39-47, 2013

[10] S. Deb, S. Gope, A. K. Goswami, "Generator rescheduling for congestion management with incorporation of wind farm using artificial bee colony optimization technique", IEEE India Conference, pp. 1-6, 2013

[11] S. Deb, S. Gope, A. K. Goswami, "Congestion Management Considering Wind Energy Sources using Evolutionary Algorithm", Electric Power Components and Systems, Vol. 43, pp. 723-732, 2015

[12] M. Ghofrani,, A. Arabali, M. Etezadi-Amoli, M. S. Fadali, "A Framework for Optimal Placement of Energy Storage Units Within a Power System With High Wind Penetration", IEEE Transactions on Sustainable Energy, Vol. 4, No. 2, pp. 434-442, 2013

[13] H. Lund, G. Salgi, B. Elmegaard, A. N. Andersen, "Optimal operation strategy of compressed air energy storage (CAES) on electricity spot market with fluctuating price", Applied Thermal Engineering, Vol. 29, pp. 799-806, 2009

[14] G. Grazzini, A. Milazzo, "Thermodynamic analysis of CAES/TES systems for renewable energy plants", Renewable Energy, Vol. 33, pp. 1998-2006, 2008

[15] H. Ibrahim, R. Younès, A. Ilinca, M. Dimitrova, J. Perron, "Study and design of a hybrid wind-diesel-compressed air energy storage system for remote areas", Applied Energy, Vol. 87, pp. 1749-1762, 2010

[16] S. Mirjalili, "Moth Flame Optimization Algorithm-A novel nature inspired heuristic paradigm", Knowledge Based System, Vol. 89, pp. 228-249, 2015

[17] "Database: World temperatures- weather around the world", available at www.timeanddate.com/weather

[18] S. Dawn, P. K. Tiwari, "Improvement of economic profit by optimal allocation of TCSC \& UPFC with wind power generators in double auction competitive power market", Electric Power and Energy Systems, Vol. 80, pp. 190-201, 2016 